\title{
Failure analysis of Rotating Blades of Low- pressure Steam Turbine Rotors and Possibility of Prediction Corrosion-fatigue Ruptures
}

\author{
Josef Kasl ${ }^{1, *}$, Miroslava Matějová ${ }^{1}$, and Jakub Mrštík ${ }^{1}$ \\ ${ }^{1}$ VZÚ Plzeň, Tylova 1581/46, 30100 Plzeň, the Czech Republic
}

\begin{abstract}
Over the last few years, corrosion fatigue fractures initiating from corrosion pits have been a root cause of failures of rotating blades of the third stage of the low-pressure parts in several 200 MW turbines in ČEZ a.s. power stations. This contribution deals with the analysis of several of these failures. Metallurgical investigation of the blades showed that the cause of the failures was the initiation and growth of a fatigue crack from a corrosion pit. ČEZ, a.s. has developed, based on the knowledge obtained by EPRI (Electric Power Research Institute), a methodology which can, in real conditions during checks of turbines, reliably detect the parameters of corrosion pits and predict the possibility of development of fatigue damage from detected pits. The process of methodology and its uncertainties (influence of filling of pits with oxides, cyclic stress calculations, and the selection of the geometric factor Y) are summarized.
\end{abstract}

\section{Introduction}

Quite a large portion of the forced idle times of the blocks of thermal and nuclear power stations is connected with defects in their turbines. One of the most significant problems of the flow part of low pressure (LP) components is stress corrosion cracking and corrosion fatigue. These defects, which most often develop from initial corrosion pits, are usually related to the presence of a higher number of corrosively aggressive impurities in the steam that accumulate in a film on the surface of the components during operation or during shutdowns in the wet parts of turbines.

Over the last few years, corrosion fatigue fractures initiating from corrosion pits have been a root cause of failures in several $200 \mathrm{MW}$ turbines in ČEZ a.s. power stations. Based on the membership of ČEZ a.s. in the P65 programme in EPRI (since 2014), a methodological procedure enabling the evaluation of fatigue crack development in the rotating blades of low-pressure components of steam turbines when cracks are initiated from corrosion pits on the surface of blades was obtained. Many years of effort by EPRI to elaborate the methodology for evaluating the influence of corrosion-erosion pits on the initiation of corrosion-fatigue cracks of the blades of the LP rotors of the steam turbines located in the phase transition zone (Wilson line) have been concentrated on the "Program

*Corresponding author: kasl@ vzuplzen.cz 
on Technology Innovation: "Development of a Corrosion-Fatigue Prediction Methodology for Steam Turbine Blades". The results of works in the field of corrosion chemistry, fatigue testing, fracture mechanics, and bladed-disk dynamics are concentrated in the EPRI technical reports [1-3]. However, the practical application of the EPRI procedure brings many new aspects that are not known and implemented by default in the ČEZ Group and that must be solved in order to apply the procedure. Based on these facts, the project "Turbines - development of a methodology for checking blades using information from EPRI" was proposed and subsequently accepted. One of its three principal objectives is to implement a diagnostic procedure which will make monitoring and evaluating the influence of pit corrosion on the surface of the rotating blades of the LP components of steam turbines in thermal and nuclear power stations possible with respect to the potential development of fatigue damage of these blades.

This contribution deals firstly with an example of analysis of the last failed blade in the power station in Počerady and secondly with the current state of application of the methodology of evaluation of the corrosion pits on the blades of the steam turbines from point of view of the susceptibility of fatigue failure.

\section{Results}

\subsection{Failure of the blade in the power station in Počerady}

In June 2016 a failure of the LP rotor of a 200 MW turbine occurred in the power station in Počerady as a consequence of a complete break-off of one of the rotating blades from the third stage.

The blade was made of stainless chrome steel R-M-AK 1.9 (X12Cr13, 1.4006, AISI 410). The analysis of the blade was carried out by the standard method and included a fractographic analysis of the fracture surface, determination of non-metallic inclusion content and the microstructure, and determination of microhardness. Furthermore, chemical and phase compositions of the material in the corrosion pit were analysed by ED microanalysis and X-ray diffraction. The mechanical properties were not verified because of the small size of the specimen.

Fractographic analysis was performed. An overall view of the fracture surface is shown in Fig. 1. There was spreading of a fatigue crack in the blade which was initiated from the corrosion pit lying near the trailing edge on the side of the gutter at a distance of $19 \mathrm{~mm}$ from the blade root (Fig. 1 - marked with an arrow). More beachmarks can be localized on the fracture surface that were, based on the operating history, used for determining the chronology of the crack growth. The area of ductile final fracture lies by the leading edge. Fig. 2 shows the corrosion pit. The average concentrations of the detected elements in the material filling the corrosion pit (in wt. \%) were $\mathrm{Fe}-43.81 ; \mathrm{O}-34.8 ; \mathrm{Cr}-13.8$; $\mathrm{Si}-5.4$; $\mathrm{Al}-0.7 ; \mathrm{Cu}-0.5 ; \mathrm{S}, \mathrm{Cl}, \mathrm{Ca}-0.2 ; \mathrm{K}, \mathrm{Ni}-0.1$. The presence of magnetite was proved by $\mathrm{X}$-ray phase analysis. Appearance of the fracture surface observed using scanning electron microscopy (SEM) is shown in Fig. 3.

Chemical composition of the steel material corresponded to the specification of the material manufacturer.

Microstructure of the material was formed of fine tempered martensite with a very small fraction of $\delta$-ferrite and a linear network of carbides on the boundaries of austenitic grains (Fig. 4). The average microhardness was 232 HV0.5 and hardness HB 222. No abnormal non-metallic inclusions content was found. 
Therefore, the blade material complied with the specification of the manufacturer. The cause of the failure was the same as for the failures being investigated which occurred in past years.

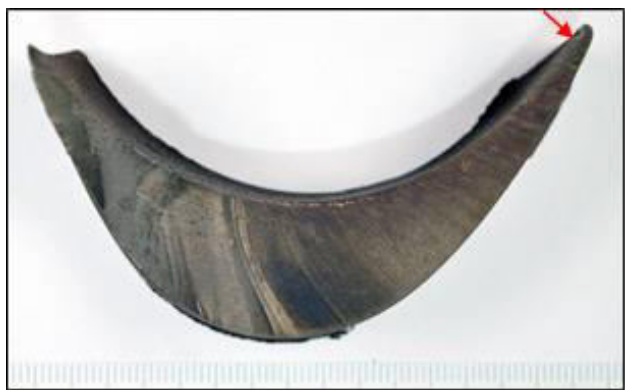

Fig. 1. Fracture surface.

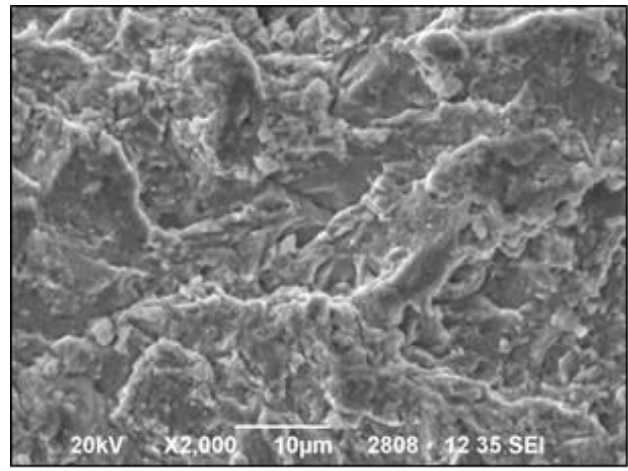

Fig. 3. Fracture surface - detail (SEM).

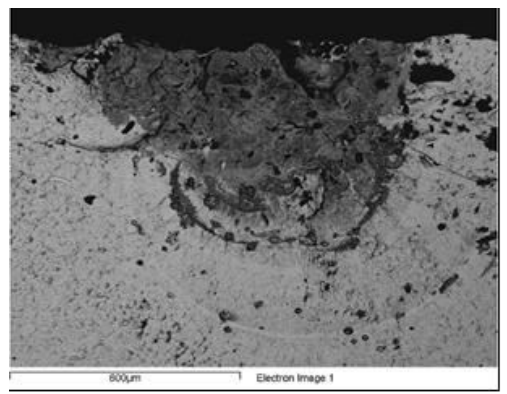

Fig. 2. Corrosion pit (SEM).

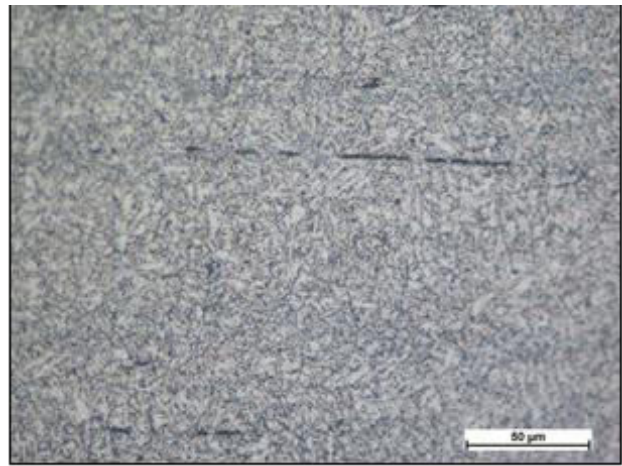

Fig. 4. Microstructure - light microscopy.

\subsection{EPRI methodology for evaluating the corrosion pits from the point of view of occurrence of fatigue cracks}

\subsubsection{Principle of methodology}

The central idea for elaborating the methodology is the precondition that the corrosion pits created on the surface of the blade make notches, and by using the methods of linear fracture mechanics it is possible to find out the values of the fatigue parameters of the respective blade material under which a crack does not spread. It is supposed that it is sufficient to characterize the state of "non-spreading" with just two parameters, i.e. smooth (without notches) specimen endurance limit $\sigma_{\mathrm{ac}}$ and threshold cyclic stress intensity limit $\Delta \mathrm{K}_{\text {th }}$ determined in the open air at a temperature of $80{ }^{\circ} \mathrm{C}$. The entire EPRI project was focused on finding the critical values of mutually related pairs - the size of the corrosion pit and stress at the place of occurrence of the pit under which the initiation of a fatigue crack does not occur.

The basis for evaluating the critical size of the corrosion pit is the Kitagawa-Takahashi diagram modified by El Haddad (KTHD). The Kitagawa-Takahashi graph [4] contains two 'Kitagawa lines' in the coordinates of stress vs. the notch size, in the given case - the depth of the corrosion pit. One of them is the constant $\Delta \sigma_{0}$ equal to the double value $\sigma_{\mathrm{ac}}$ :

$$
\Delta \sigma(a)=\Delta \sigma_{0}(\text { the graph is the constant (1)) }
$$


and the other one is created by the dependence of threshold cyclic stress intensity limit $\Delta \mathrm{K}_{\mathrm{th}}$ on the notch size (pit depth) a:

$$
\Delta \sigma(a)=\left(\Delta K_{t h}\right) /\left(Y(\pi a)^{1 / 2}\right)(\text { the graph is the linear dependence (2)) }
$$

where $\mathrm{Y}$ is a geometric factor. This graph was completed by El Haddad, Topper and Smith [5] with another 'El Haddad curve' to which the Kitagawa lines create asymptotes:

$$
\Delta \sigma(a)=\left(\Delta K_{t h}\right) /\left(Y\left(\pi\left(a+a_{0}\right)\right)^{1 / 2}\right)(\text { the graph is the curve (3) })
$$

where $\mathrm{a}_{0}$ is an intrinsic pit depth which is given by the intersection point of both Kitagawa lines according to the relations (1) and (2):

$$
a_{0} \equiv(1 / \pi)\left(\Delta K_{t h} / Y \Delta \sigma_{0}\right)^{2}
$$

The curves are the material characteristics for the stress ratio parameter $\mathrm{R}$ :

$$
R=\sigma_{\min } / \sigma_{\max }=\left(\sigma_{m}-\sigma_{a}\right) /\left(\sigma_{m}+\sigma_{a}\right)
$$

when it is considered that loading is carried out between two constant levels of stress maximum $\sigma_{\max }$ and minimum $\sigma_{\min }$ which determine the amplitude of stress $\sigma_{\mathrm{a}}$ and mean stress $\sigma_{\mathrm{m}}$.

The experimental result shows that all the cracked specimens are above line (3), all the non-cracked specimens are below, or more precisely to the left of lines (1) and (2). Therefore the Kitagawa-Takahashi-El Haddad (KTHD) diagram may be divided into three areas:

A - above and to the right of (1) and (2); the cracks initiated in the pit will grow

$\mathrm{B}$ - below (3); the cracks may initiate in the pits but will not grow

$\mathrm{C}$ - between (1) and (2) and (3) it is possible that the cracks will most probably develop (see Fig. 5).

The preconditions for processing and using the methodology are as follows:

a) To know two necessary material parameters of the tested blade for the construction of a KTHD. Experimentally, the double of the smooth specimen endurance limit $\Delta \sigma_{0}$ and threshold cyclic stress intensity limit $\Delta \mathrm{K}_{\mathrm{th}}$ must be determined for a chosen environment (the normal atmosphere is used in the methodology) for some values of R. It is necessary to determine regression equations for calculating the respective parameters for any value $\mathrm{R}$.

b) To find positions of corrosion pits on the blade and their dimensions.

c) To calculate the mean stress and stress amplitude and to determinate the value of R.

d) To construct KTHDs and find position of individual pits (their depths) in them.

\subsubsection{Application of methodology}

KTHD were constructed for steels AK 1.9 (X12Cr13); AK1TD; 1.4938 (X12CrNiMoV123/Böhler T552/1.4939/X12CrNiMo12) and Böhler T671, for the blades of stages L-0 and L-1 for 11 models of the blades of the turbines with outputs 200, 250, 270 and $660 \mathrm{MW}$ operated on power stations of ČEZ a.s. This papers deals only with blades of third stage of LP rotor $200 \mathrm{MW}$ whose blades really failed.

The used process was in accordance with above described methodology. The experimental values were determined for the endurance limit for $\mathrm{R}=-1 ; 0.1 ; 0.5$ and 0.8 and for threshold cyclic stress intensity limit for $\mathrm{R}=0.1 ; 0.5$ and 0.85 . Approximation by the Gerber parabola was used to calculate the endurance limit and a polynomial of the third order for threshold cyclic stress intensity limit. 
Geometric parameters of the corrosion pits in the given position on the blade surface depth a (and possibly half-width c) were determined on the rotors with the blades by laser scanning or imprints.

Static and dynamic stresses in a given place (the position of an occurrence of the corrosion pit) on the blade surface were calculated using method of finite elements (MFE). If we know the acting static stress $\sigma_{\mathrm{m}}$ and the amplitude of the cyclic stress $\sigma_{\mathrm{a}}$, the respective parameter $\mathrm{R}$ was determined and the KTHD constructed. The observed size of the corrosion pits and local acting stress can then be drawn in the diagram and the position of points in relation to the El Haddad curve can be found. The pit must have a size exceeding the critical size $\mathrm{a}_{\mathrm{cr}}$ and the rate of the crack growth must be higher than the rate of growth of the corrosion pit. The possibility of corrosion growth of a pit is difficult to describe and is not dealt with in the methodology. An example of a KTHD for the initiation corrosion pit on a failed blade from the power station in Počerady is shown in Fig. 5.

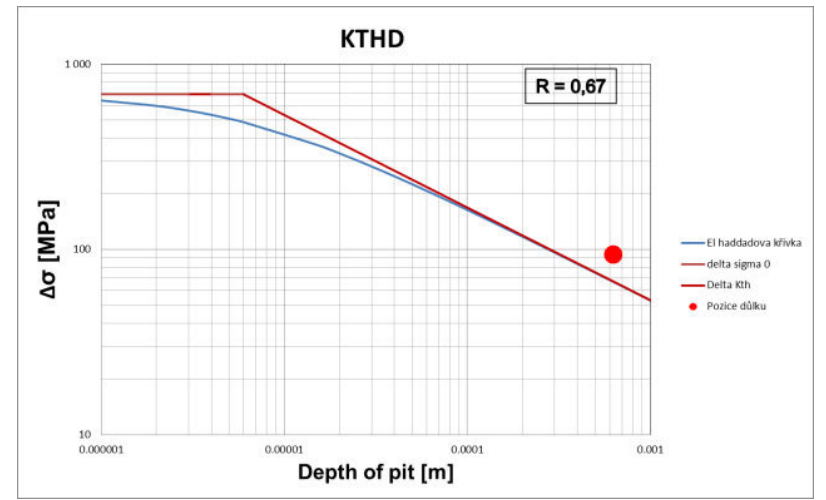

Fig. 5. Kitagawa-Takahashi-El Haddad Diagram for corrosion pit of the failed blade from power station Počerady (sample T4).

\subsubsection{Uncertainties of the applied methodology}

In the whole procedure of evaluation of the disposition of the corrosion pits to the development of fatigue cracks there are many uncertainties that may influence reliability and the informative capability of the method.

The first problem is scanning the geometric parameters of the corrosion pits. Apart from problems with availability of single localities on the surface of the blades placed in the rotor disk, it is necessary to realize that the corrosion pits usually have irregular and complicated shapes and are often filled with oxidation products and deposited material (Fig. 6 and 7). Thus, for many pits, determination of their dimensions, especially depth, may be inaccurate. Any quit satisfactory procedure how to clean pits on the rotor was found. More than fifty pits on blades ere underwent to metallographical analysis with goal to find some correlation between measured depth of pit (with deposit) $a_{\text {mes }}$ and real depth $a_{\text {cor }}$ or between width and depth of the pit $[6,7]$. However no unique correlations were found. The practise how to solve this challenge was chosen a correlation equation found for the large pits lying in the critical area on the blade surface (near the trailing edge and the platform of the blade):

$$
a_{c o r}=195+0.19 a_{\text {mes }}[\text { both values in } \mu \mathrm{m}]
$$

and to optimize a geometric parameter $\mathrm{Y}$ (see a paragraph hereinafter).

Two basic parameters describing fatigue properties of the given blade steel must be known to construct KTHD diagrams; namely twice the smooth specimen endurance limit 
$\Delta \sigma_{0}$ and the threshold cyclic stress intensity limit $\Delta \mathrm{K}_{\mathrm{th}}$. They are determined for a limited number of values of the stress ratio parameter $\mathrm{R}$ - in our case for three to four values. However, it is necessary to know these parameters for any $\mathrm{R}$, which creates the need to calculate these values from regression equations. Their accuracy will be, in principle, better the more experimental data we have at our disposal, and a more accurate model for the dependence of a given quantity on $\mathrm{R}$ will be selected. So, this risk may be reduced by increasing the number of tests carried out, which, of course, takes time and money.

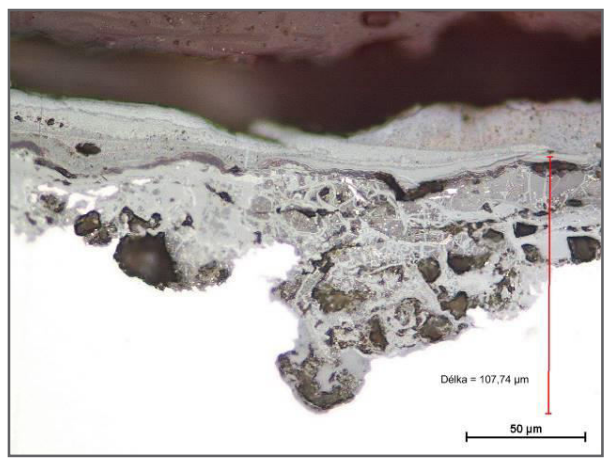

Fig. 6. Corrosion pit (LM).

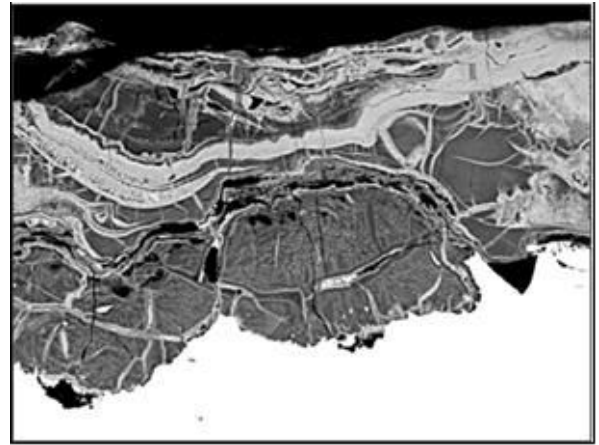

Fig. 7. Corrosion pit (SEM).

By far the largest problem is the determination of static and especially dynamic stress on the blade at the site of the detected corrosion pit by mathematical modelling using finite element method. Unfortunately, real deflections of the blades in various states of turbine operation are not known, in other words, they are known from measurements of the type BTT (blade tip timing) only for some (last) stages of LP rotors and for only some turbines. For blades from 200 MW blocks, an end deviation of $1 \mathrm{~mm}$ is assumed, but without any experimental support. In the EPRI methodology, when there is a lack of information, especially about dynamic stress, it is recommended to use a "straight" stress range value $\Delta \sigma$ 30 - $40 \mathrm{MPa}$.

Another major problem is the determination of the geometric factor Y. When developing the EPRI methodology, after many attempts to determine the Y value by calculation, we gave up and it was determined so that the experimental results of the tests of specimens with artificial pits of a given size "match" the best in the KTHD diagram, i.e. that the broken specimens are above the El Haddad curve and the unbroken specimens are below it. A value of 0.42 was determined in this way for both steels tested in the EPRI works.

At the present time all the detailed documented failures of the blades in the LP components of the steam turbines in the power stations of the ČEZ Group happened on blocks with an output of $200 \mathrm{MW}$ on one stage on blades of one material. Therefore, the necessary data about the corrosion pits of above-critical size were available, at least in a certain scope and accuracy. From recent measurement of the corrosion pits by laser scanning the dimensions of the pits with subcritical sizes were also known. So, it was possible to verify this methodology by means of these pits.

The parameters of four pits from which fatigue cracks were provably spreading (marked as specimens $\mathrm{T} 1$ to T4) and the parameters of the ten "worst" pits from the last measurements [9] from which fatigue cracks did not spread (marked as specimens N1 to N10) were used for testing the methodology for the blades of the L-1 stage of LP rotors of turbines with an output of $200 \mathrm{MW}$. Unfortunately, for three of the failed blades (T1 to T3), we no longer have the real specimens and the dimensions of the pits and their positions were determined only based on the visual documentation contained in the reports [9-11], 
and therefore they may be slightly inaccurate. Specimen T4 is the failed blade from the power station in Počerady.

The stress amplitude range ratio at the place of the pit and corresponding to stress on the El Haddad curve was calculated for all the pits. This ratio should be higher than 1 for blades with cracks and below 1 for blades without cracks.

Various values of parameter $\mathrm{Y}$ in combinations with correlation equations for correction of measured pit's depth were tested. The best fit of parameter was 0.50 . So, by an appropriate choice of geometric parameter Y, KTHD can be "adjusted" so that the risk pits of critical size can be determined by the methodology.

Another condition necessary for the successful application of the methodology is a knowledge of the history and the outlook for turbine operation, or more precisely for a rotor with blades in terms of the number of starts, shutdowns, operation time periods at limited output, etc. Therefore, it means having these data in sufficient scope and readily at our disposal.

\section{Summary}

The fractographic and material analyses of the failed blade of the third running wheel of the LP rotor of the $200 \mathrm{MW}$ turbine in the power station in Počerady were carried out. The results of the analysis showed that the causes of the failure were similar to the broken blades of the previous LP rotors in the power stations of ČEZ a.s., i.e. the initiation and spreading of the corrosion-fatigue cracks from the pits lying near the trailing edge of the blade.

This paper presents the current state of the development of a methodology that should provide an instrument for detecting the corrosion pits from which the fatigue cracks will most probably initiate. By replacing the respective blades, significant damage could be avoided. In the methodology there are several critical input parameters which may significantly influence the reliability of the procedure in terms of failure to detect the critical pits and, on the other hand, their overestimation, resulting in unnecessary replacements of blades. These parameters are especially the uncertainties of the pit depth, the stress calculations, mainly their dynamic component, and the selection of the geometric factor $Y$.

This work has been carried out with the financial support of the project TE01020068.

\section{References}

1. Program on Technology Innovation: Development of a Corrosion-Fatigue Prediction Methodology for Steam Turbines: Experimental results 2009-2010. EPRI, Palo Alto, CA: 2010. 1023196

2. Program on Technology Innovation: Development of a Corrosion-Fatigue Prediction Methodology for Steam Turbine Blades: AISI 403/410 (12\% Cr) and 17-4PH Blade Steels. EPRI, Palo Alto, CA: 2013. 10256208

3. Program on Technology Innovation: Development of a Corrosion-Fatigue Prediction Methodology for Steam Turbine Blades: AISI 403/410 (12\% Cr) and 17-4PH Blade Steels. EPRI, Palo Alto, CA: 2015. 3002005107

4. H. Kitagawa, S. Tahashi, Proc. of the Second International Conference on Mechanical Behavior of Materials. Metals Park, OH: American Society for Metals; p. 627 (1976)

5. M. El Haddad, T.H. Topper, N. Smith, ASME Engrg. Matls. Technol. 103, 91 (1981) 
6. P. Bublíková, R. Janura, V. Habrcetl, Technical report CV Řež s.r.o. 1203/16, Plzeň (2016)

7. M. Matějová, J. Kasl, Technical report VZÚ Plzeň VYZ/TZ/52/16/017, Plzeň (2016)

8. P. Zahrádka, J. Patera, Technical report CV Řež s.r.o. 1241/16, Plzeň (2016)

9. J. Siegl, I. Nedbal, P. Haušild, Technical report E-KMAT-835/11 FJFI ČVUT in Praha, (2011)

10. J. Siegl, I. Nedbal, P. Haušild, Technical report E-KMAT-874/11 FJFI ČVUT v Praze, (2013)

11. J. Siegl, O. Kovařík, I. Nedbal, Technical report E-KMAT-882/13 FJFI ČVUT v Praze, (2013) 